\title{
INTRODUCTION \\ Neurosurgery, psychiatry, and function: the history of altering behavior, thought, and function through neurosurgery
}

\author{
Mark C. Preul, MD, ${ }^{1}$ T. Forcht Dagi, MD, ${ }^{2}$ Charles J. Prestigiacomo, MD, ${ }^{3}$ and \\ Chris A. Sloffer, MD, MBA4
}

\begin{abstract}
1Department of Neurosurgery, Barrow Neurological Institute, St. Joseph's Hospital and Medical Center, Phoenix, Arizona; ${ }^{2}$ The School of Medicine, Dentistry and Biomedical Sciences, Queen's University Belfast, Northern Ireland, United Kingdom; ${ }^{3}$ East Hanover, New Jersey; and "Bronson Neuroscience Center, and Western Michigan University Homer Stryker School of Medicine, Kalamazoo, Michigan
\end{abstract}

$\mathrm{S}$ CIENTISTS and clinicians have navigated a tortuous road in trying to understand and to influence the relationship between the brain and the mind. Indeed, the history of the neurosciences is full of efforts to alter behavior, thought, and function through surgical intervention. From early attempts by Swiss psychiatrist Gottlieb Burckhardt in 1888 to Egas Moniz's Nobel Prize-winning work on frontal leucotomy in the mid-1930s to deep brain stimulation beginning in the 1960s, neurosurgeons have attempted to apply specific surgical methods to the modulation of complex brain functions. History has shown this to be a journey filled with tremendous promise and enormous pain. Whether society has been, on the whole, a beneficiary or a victim is open to debate.

This issue of Neurosurgical Focus is devoted to the history of these interventions in the context of broader neurosurgical contributions to the understanding of the mind. It addresses some of the dubious, disturbing, and controversial, albeit undeniably brilliant, roles that surgeons and surgery have played in the treatment of patients with psychiatric illness. It also probes the social factors that made psychiatric surgery plausible and, at times, acceptable.

The issue is organized according to topic, demonstrating ways in which early scientific observations of temporal ablation and frontal lobe function naturally lead to fascinating investigations into the effects of leucotomy and lobotomy. These forays led neurosurgeons to contemplate the potential of undertaking cortical surgery for the treatment of mental illness based on experimental observations presented at the 1935 International Neurological Congress in London. Neurosurgeons have not been the only protag- onists in this history; psychiatrists and neurologists have also played central roles. Included is a paper on Walter Freeman's lobotomy procedure that focuses uniquely on ethics and the media and another relating to the controversy of topectomy versus leucotomy and the involvement of J. Lawrence Pool. The next three papers in the middle of the issue give vivid glimpses into the lives of people with mental illness and the interplay between neurosurgery and psychiatry in organized attempts to plan and manage surgery to treat the behavioral rages and the self-torture of psychiatrically ill patients, the general depravity of institutional care, and the lack of effective treatment for patients with mental illness. Two additional articles provide engaging reading on the involvement of figures such as Jean Talairach and Robert Heath, and another paper explores the history of psychosurgery in Japan. Finally, there are two contributions that review hypothalamic surgery for aggressive behavior, which is, of course, the very problem leucotomy and lobotomy were originally meant to manage. Two papers stimulated editorial commentaries. Two others are accompanied by video abstracts.

One may be tempted to believe narrowly that there is only a dark side to psychosurgery, an impression easily garnered from some of the work of Egas Moniz and later the showmanship and personality of Walter Freeman (Fig. 1). Nevertheless, the history of psychosurgery does not entirely merit that conclusion. Advances in technology at the end of the 19th century did lead to the idea that functionally targeted surgical interventions were plausible. In the 1920s Wilder Penfield began incredible brain mapping and functional exploration, while also considering the re- 


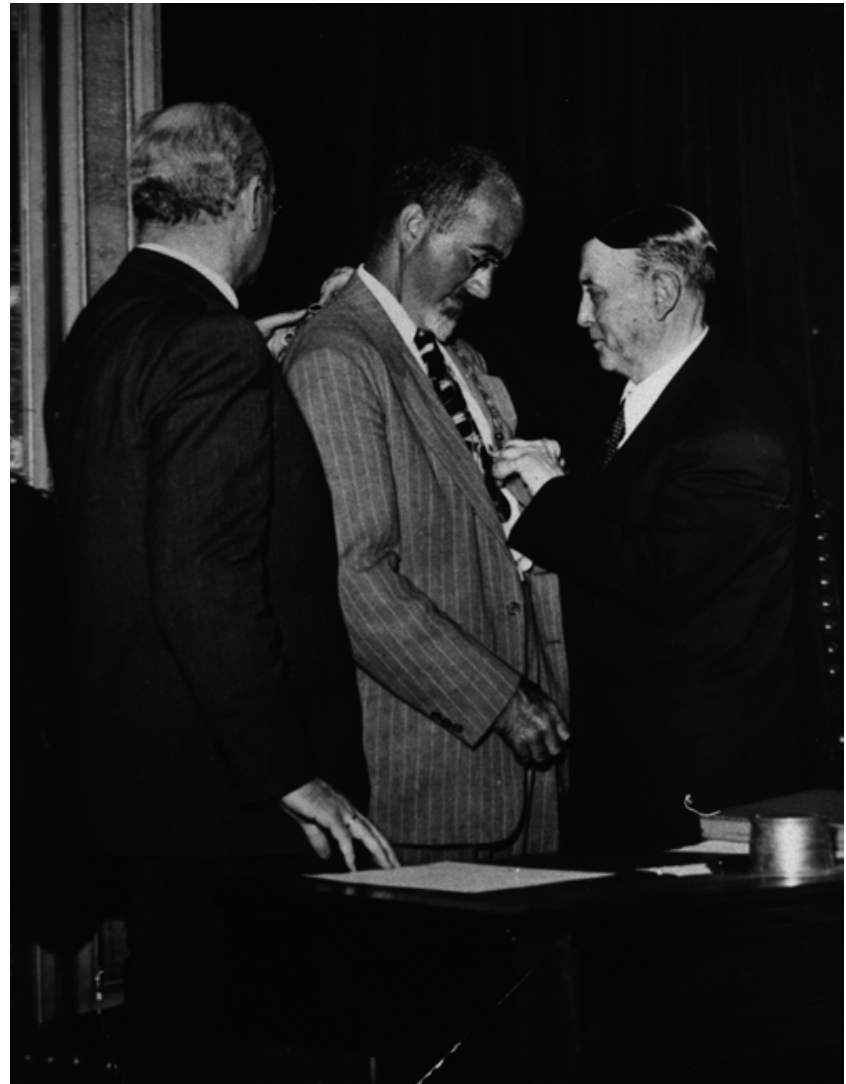

FIG. 1. From the "leucotomist" to the "lobotomist," Egas Moniz (right) awarding Walter Freeman a medal with the emblem of the Academia das Ciências de Lisboa (The Academy of Sciences of Lisbon) in Lisbon in 1948. In the summer of 1948, physicians from around the globe gathered in Lisbon, Portugal, for the First International Conference on Psychosurgery. Representatives from more than 20 nations attended and discussed information from 8000 surgical cases. The conference, organized by Walter Freeman leading a committee of surgeons and neurologists with James Watts as secretary of the conference and program committee chairman, was also a tribute to Egas Moniz. The conference was indicative of the popularity of psychosurgery and scientific interest in the treatment by 1948. The next year, Moniz received (i.e., shared) the Nobel Prize in Physiology or Medicine for his prefrontal leucotomy procedure. Photograph courtesy of the National Library of Medicine, Bethesda, MD.

lationship of the mind to the brain. There was an explosion of interest in thinking about psychiatric disease much as one might think about trauma, brain tumors, or epilepsy. Conditions in mental asylums were in many places unspeakable. Effective treatment for psychiatric disease was frustratingly elusive, particularly for individuals exhibiting violent outbursts or socially unacceptable behavior. Effective antipsychotic drugs were still 2 decades away. Not much had changed since the middle ages, and the asylums were full. Thus, leucotomy and lobotomy seemed like plausible and perhaps even miraculous solutions for psychosis and psychotic depression. Within 15 years after their introduction, these procedures were questioned and criticized; within 20 years, they were performed measurably less often; and within 35 years, they were the object of attack and derision.

We might think to ask why this aspect of neurosurgery became so emotionally charged. One good reason was the nearly random processes by which patients were selected for surgery and the loose indications that prevailed. A second was the preponderance of women undergoing leucotomy. A third was the lack of voluntary informed consent, and a fourth was the intellectual deterioration and emotional flatness that ensued postoperatively. For many critics, beyond even this damning list of errors, any attempt to meddle with personality and behavior was judged very harshly as an attack on essential humanness, on the human mind.

At the end of his career, reflecting on the existence of the mind apart from the physicality of the brain that he had largely proposed, Wilder Penfield, who vigorously began brain functional exploration in the 1920s, and who had perhaps performed more brain mapping, more cortical resections, and more cortical ablations than any other neurosurgeon of his time, wrote:

Throughout my own scientific career I, like other scientists, have struggled to prove that the brain accounts for the mind. But now, perhaps, the time has come when we may profitably consider the evidence as it stands, and ask the question: Do brain-mechanisms account for the mind? Can the mind be explained by what is now known about the brain? If not, which is the more reasonable of the two possible hypotheses: that man's being is based on one element, or on two?

On the basis of either hypothesis the nature of the mind remains, still, a mystery that science has not solved. But it is, I believe, a mystery that science will solve some day. In that day of understanding, I predict that true prophets will rejoice, for they will discover in the scientist a long-awaited ally in the search for Truth.

We hope this issue of Neurosurgical Focus on the history of neurosurgery will be enlightening and enjoyable reading.

https://thejns.org/doi/abs/10.3171/2017.6.FOCUS17430

\section{References}

1. Penfield W: The Mystery of the Mind. A Critical Study of Consciousness and the Human Brain. Princeton, NJ: Princeton University Press, 1975, xiii

\section{Disclosures}

The authors report no conflict of interest. 